\title{
Endogenous Cycles in a Two-sector Overlapping Generations Model under Intertemporal Substitutability
}

\author{
Thomas Seegmuller*
}

March 18, 2003

\section{Introduction}

In his seminal work, Grandmont (1985) studies the emergence of endogenous fluctuations in a perfectly competitive monetary overlapping generations model. It is well-known that the occurrence of an endogenous cycle requires a strong income effect. More recently, Lloyd-Braga (2000) shows that the occurrence of cycles requires a weaker income effect when returns to scale are increasing. However, the existence of deterministic fluctuations is not compatible with intertemporal substitutability and an increasing labor supply.

In this paper, we analyze local dynamics in a two-sector monetary overlapping generations economy. We show that, in contrast to one-sector models, deterministic cycles may occur under intertemporal substitutability.

Several economists have already shown that endogenous cycles can emerge in overlapping generations models characterized by intertemporal substitutability or an increasing labor supply, but none of them has covered a multi-sector monetary economy. Reichlin (1986) introduces a technology with two inputs, labor and capital. In his framework, endogenous cycles can emerge if the two factors are sufficiently complementary. In a monetary

*BETA-Theme, Louis Pasteur University, 61, avenue de la Forêt-Noire 67085 Strasbourg Cedex France, Tel: (33) 3902420 98, Fax: (33) 3902420 71, e-mail: seegmu@cournot.u-strasbg.fr. We would like to thank Antoine d'Autume, Rodolphe Dos Santos Ferreira, Teresa Lloyd-Braga, Hubert Stahn, Alain Venditti and two anonymous referees for helpful comments and suggestions. All remaining errors are ours. 
model, Jacobsen (2000) introduces monopolistic competition in good and labor markets. Endogenous cycles can occur when labor supply is increasing, if monopoly profits, due to the market power of producers, are high enough. Aloi, Dixon, and Lloyd-Braga (2000) analyze a small open economy without capital accumulation. They show that endogenous cycles can appear because households can substitute consumption of non-traded goods for consumption of traded goods.

In this paper, we introduce two sectors in a monetary overlapping generations model. In contrast to a lot of contributions which consider one consumption good and one investment good, ${ }^{1}$ we assume that there are two consumption goods. In each sector, one of them is produced by firms using a constant returns to scale technology and only one input, labor. Since firms benefit from sector specific externalities, returns to scale are increasing at the social level. In each sector, households supply labor to the firms of their sector when young, and consume the two goods produced in the economy when old. ${ }^{2}$ Since leisure and future consumption are gross substitutes, the labor supply is an increasing function of the real wage.

In this economy, the dynamics are determined by a two-dimensional dynamic system. We first establish the existence of a steady state and analyze the uniqueness or multiplicity of stationary solutions.

Secondly, we study the local stability of the steady state and the occurrence of bifurcations. Using the geometrical method developed by Grandmont, Pintus, and de Vilder (1998), we show that local indeterminacy requires sufficiently strong increasing returns to scale. As in Benhabib and Farmer (1994) or Aloi, Dixon, and Lloyd-Braga (2000), the slope of labor demand must be greater than the slope of labor supply. However, more interestingly, endogenous deterministic cycles can emerge if households prefer to consume the good produced in the other sector. Indeed, in this case, aggregate consumption and labor can move in opposite directions in each sector and these deterministic cycles are compatible with intertemporal substitutability. The interaction between the two sectors is the key component for the occurrence of these fluctuations. Furthermore, it is also interesting to notice that our result does not depend on the substitutability or complementarity between the two goods, but only on the marginal propensity to consume each good.

Finally, our analysis can be related to the results obtained in two-sector optimal growth models. Indeed, in these models, cycles of period two can

\footnotetext{
${ }^{1}$ See among others Benhabib and Farmer (1996), Benhabib and Nishimura (1998), Benhabib, Nishimura, and Venditti (2002), Galor (1992) and Harrison and Weder (2002).

${ }^{2}$ It means that households are specialized in production but not in consumption. A similar specification has been used by Chatterjee, Cooper, and Ravikumar (1993).
} 
occur if the consumption good is more capital intensive than the investment good (Benhabib and Nishimura (1985)), whereas in our work, the utility function must be more intensive in the good produced in the other sector than in the good produced in the sector.

This paper is organized as follows. In section 2, we present the model. In section 3 , we analyse the steady state. In section 4 , we study the emergence of endogenous fluctuations. We conclude in section 5 .

\section{The Model}

We consider an overlapping generations model with perfect foresight and discret time $t=0,1,2 \ldots, \infty$. There are two sectors $i(i=1,2)$ in the economy and all markets are perfectly competitive. In each sector, one good is produced by firms using only one input: the labor supplied by households of the sector. All firms have identical technology exhibiting constant returns to scale, but returns to scale are increasing at the social level because there are sector specific externalities. Since population is constant over time, we consider in each sector a representative household living for two periods. When young, the household works and saves money, and when old, it spends money and consumes the two goods produced in the economy. Money is the numéraire and the only asset. At the first period, there is a generation of old households endowed with one unit of money in each sector. Now, we present more formally the model.

\subsection{Households}

A representative household of sector $i$ solves the following utility optimization problem:

$$
\operatorname{Max} U\left(C_{i i}^{t+1}, C_{i j}^{t+1}\right)-A \frac{l_{i t}^{v}}{v}
$$

such that

$$
p_{i t+1} C_{i i}^{t+1}+p_{j t+1} C_{i j}^{t+1}=w_{i t} l_{i t}
$$

with $i \neq j$. $C_{i i}^{t+1}$ (respectively $C_{i j}^{t+1}$ ) is the next period consumption of good $i$ (respectively good $j$ ) in sector $i, l_{i t}$ is the labor supply, $p_{i t+1}$ (respectively $p_{j t+1}$ ) is the next period price of good $i$ (respectively good $j$ ) and $w_{i t}$ is the nominal wage. Concerning parameters, $v$ is strictly greater than 1 and $A>0$ is a scaling parameter. We further consider that the function $U(x, y)$ is characterized by: 
Assumption 1 The function $U(x, y)$ is continuous for $x \geq 0$ and $y \geq 0$ and has continuous derivatives of every required order for $x>0$ and $y>0$. Moreover, $U(x, y)$ is increasing in $x$ and $y$, strongly quasi-concave, homogeneous of degree one and such that the indifference curves do not cross the axes.

We can notice that the utility function $U\left(C_{i i}^{t+1}, C_{i j}^{t+1}\right)$ can be interpreted as the future aggregate consumption of households of sector $i$. Moreover, the assumptions on the utility function mean that leisure and future consumption are gross substitutes.

We can now determine the optimal consumptions:

$$
\begin{gathered}
C_{i i}^{t+1}=\alpha\left(\eta_{t+1}\right) \frac{w_{i t} l_{i t}}{p_{i t+1}} \\
C_{i j}^{t+1}=\left(1-\alpha\left(\eta_{t+1}\right)\right) \eta_{t+1} \frac{w_{i t} l_{i t}}{p_{i t+1}}
\end{gathered}
$$

where $\eta_{t+1} \equiv p_{i t+1} / p_{j t+1}$ and $\alpha\left(\eta_{t+1}\right) \in(0,1)$ represents the marginal propensity to consume the good produced in the sector. When $\alpha\left(\eta_{t+1}\right)>1 / 2$, the household prefers to consume the good produced in his sector, whereas when $\alpha\left(\eta_{t+1}\right)<1 / 2$, the household prefers to consume the good produced in the other sector. If we note:

$$
\frac{C_{i i}^{t+1}}{C_{i j}^{t+1}}=\frac{\alpha\left(\eta_{t+1}\right)}{\left(1-\alpha\left(\eta_{t+1}\right)\right) \eta_{t+1}} \equiv H\left(\eta_{t+1}\right)
$$

the elasticity of substitution between the good produced in the sector and the good produced in the other sector is defined by:

$$
\sigma\left(\eta_{t+1}\right)=-\frac{H^{\prime}\left(\eta_{t+1}\right) \eta_{t+1}}{H\left(\eta_{t+1}\right)}=1-\frac{\alpha^{\prime}\left(\eta_{t+1}\right) \eta_{t+1}}{\alpha\left(\eta_{t+1}\right)\left(1-\alpha\left(\eta_{t+1}\right)\right)}
$$

We can notice that $\alpha$ is increasing when there is complementarity $(\sigma<1)$ and is decreasing when there is substitutability $(\sigma>1)$.

Substituting (2) and (3) into the function $U$, we obtain:

$$
U\left(\alpha\left(\eta_{t+1}\right),\left(1-\alpha\left(\eta_{t+1}\right)\right) \eta_{t+1}\right) \frac{w_{i t} l_{i t}}{p_{i t+1}} \equiv U^{*}\left(\eta_{t+1}\right) \frac{w_{i t} l_{i t}}{p_{i t+1}}
$$

This function linearly depends on the wage income. Furthermore, using the first order condition $U_{1}=U_{2} \eta_{t+1}{ }^{3}$ and Euler identity $U=U_{1} \alpha+$ $U_{2} \eta_{t+1}(1-\alpha)$, we have:

\footnotetext{
${ }^{3}$ In order to simplify the notations, we do not write the arguments of the functions and we note $U_{i} \equiv \partial U\left(x_{1}, x_{2}\right) / \partial x_{i}, i=1,2$.
} 


$$
U^{*^{\prime}} \eta_{t+1}=\left(U_{1}-U_{2} \eta_{t+1}\right) \alpha^{\prime} \eta_{t+1}+U_{2} \eta_{t+1}(1-\alpha)=U^{*}(1-\alpha)>0
$$

Finally, we can determine consumers labor supply:

$$
U^{*}\left(\eta_{t+1}\right) \frac{w_{i t} l_{i t}}{p_{i t+1}}=A l_{i t}^{v}, i \neq j
$$

Then, the elasticity of labor supply with respect to the real wage is equal to $1 /(v-1)>0$ and the labor supply is increasing.

\section{$2.2 \quad$ Firms}

In each sector, there is a continuum of firms of unit mass. They produce one final good using only one input, labor, under a constant returns to scale technology. Since there are sector specific externalities, the returns to scale are increasing at the social level. The production function can be written as follows:

$$
y_{i t}=\bar{l}_{i t}^{e} l_{i t}
$$

where $y_{i t}$ and $l_{i t}$ are, respectively, the output and the labor per firm. Moreover, $\bar{l}_{i t}$ is the labor used in production at the sector level and the parameter $e \geq 0$ represents the level of sector specific externalities.

Since all markets are perfectly competitive, the first order condition of the profit maximization can be written:

$$
\frac{w_{i t}}{p_{i t}}=\bar{l}_{i t}^{e}
$$

We notice that in the limit case where $e$ is equal to 0 , there is no externality and the returns to scale are constant at the social level. Then, the real wage is constant and equal to 1 in each sector. Before determining the intertemporal equilibrium, we further assume that $e \neq v-1$. It means that the elasticity of labor supply cannot be equal to the elasticity of labor demand.

\subsection{Intertemporal Equilibrium}

The equilibrium on the money market implies that wage earning is equal to the stock of money which is normalized to one in each sector, i.e. $w_{i t} l_{i t}=1$ $(i=1,2)$. Moreover, $\bar{l}_{i t}=l_{i t}$ at equilibrium. We deduce that $y_{i t}=l_{i t}^{1+e}$ and $w_{i t} / p_{i t}=l_{i t}^{e}$. Since internal returns to scale are constant, the profits are equal to zero, i.e. $p_{i t} y_{i t}=w_{i t} l_{i t}$. Using the relation $w_{i t} l_{i t}=1$, we deduce 
that $p_{i t}=l_{i t}^{-(1+e)}$. Substituting this last relation and the equilibrium on the money market into (8), we can now define the intertemporal equilibrium:

Definition 1 An intertemporal equilibrium with perfect foresight is a sequence $\left(l_{1 t}, l_{2 t}\right) \in \mathbb{R}_{++}^{2}, t=0,1,2 \ldots, \infty$, such that:

$$
\begin{aligned}
& U^{*}\left[\left(l_{2 t+1} / l_{1 t+1}\right)^{1+e}\right] l_{1 t+1}^{1+e}=A l_{1 t}^{v} \\
& U^{*}\left[\left(l_{1 t+1} / l_{2 t+1}\right)^{1+e}\right] l_{2 t+1}^{1+e}=A l_{2 t}^{v}
\end{aligned}
$$

Equations (11) and (12) entirely govern the dynamics of the model. They implicitly determine a two dimensional dynamic system without predetermined variable.

\section{Steady State Analysis}

In this section, we study the existence, uniqueness or multiplicity of stationary states for the dynamic system (11)-(12). Our analysis will closely follow Cazzavillan, Lloyd-Braga, and Pintus (1998) and Aloi, Dixon, and Lloyd-Braga (2000).

\subsection{Existence}

A steady state of the dynamic system (11)-(12) is a solution $\left(l_{1}, l_{2}\right)$ for all $t$ such that:

$$
\begin{aligned}
& U^{*}\left[\left(l_{2} / l_{1}\right)^{1+e}\right] l_{1}^{1+e-v}=A \\
& U^{*}\left[\left(l_{1} / l_{2}\right)^{1+e}\right] l_{2}^{1+e-v}=A
\end{aligned}
$$

In what follows we ensure the existence of a steady state, namely with $l_{1}=1, l_{2}=1$, by choosing an appropriate value of the scaling parameter $A>0$, such that:

$$
A=U^{*}(1)
$$

Given Assumption 1, there is an unique solution $A \in \mathbb{R}_{++}$to the equation (15).

Proposition 1 Under Assumption 1, let $A \in \mathbb{R}_{++}$be the unique solution of equation (15). Then $\left(l_{1}, l_{2}\right)=(1,1)$ is a stationary solution of the dynamic system (11)-(12). 


\subsection{Uniqueness versus Multiplicity}

Studying the number of steady states involves finding the number of solutions of the system (13)-(14). If we note $a \equiv\left(l_{1} / l_{2}\right)^{1+e}$, equations (13) and (14) can be written:

$$
U^{*}(1 / a) l_{1}^{1+e-v}=A \text { and } U^{*}(a) l_{2}^{1+e-v}=A
$$

Using these last two relations, the analysis of the uniqueness or multiplicity of steady states requires to study the number of solutions $a$ such that:

$$
\theta(a) \equiv \frac{U^{*}(1 / a)}{U^{*}(a)} a^{1-v /(1+e)}=1
$$

Indeed, given $a$ we are able to determine $l_{1}$ and $l_{2}$. We notice that $\theta(a)$ is a continuous positive valued function for all $a$. If $\theta(a)$ is monotonic (i.e. either $\theta^{\prime}(a)>0$ for all $a$ or $\theta^{\prime}(a)<0$ for all $a$ ), there exists one steady state, i.e. the one defined in Proposition 1. If $\theta^{\prime}(a)$ changes its sign only once then, at most two steady state solutions exist. Finally, if $\theta(a)$ is constant then, by Proposition 1, $\theta(a)=1$ for all values of $a$ and there is a continuum of steady states.

Using equation (7), we have:

$$
\frac{\theta^{\prime}(a) a}{\theta(a)}=\alpha(a)+\alpha(1 / a)-1-\frac{v}{1+e}
$$

Since $\theta^{\prime}(a)$ and $\theta^{\prime}(a) a / \theta(a)$ have the same sign, we can establish that:

Proposition 2 Under the assumptions of Proposition 1, there is an unique steady state, with $a=1$, if one of the two following conditions is satisfied:

(i) $\alpha(a)+\alpha(1 / a)>1+v /(1+e)$, for all $a>0$;

(ii) $\alpha(a)+\alpha(1 / a)<1+v /(1+e)$, for all $a>0$.

In the special case where $\alpha$ is constant, case ( $i)$ or (ii) occurs, except when $\alpha=(1+v /(1+e)) / 2$. In this latter configuration, there is a continuum of steady states.

We can remark that when the returns to scale are constant $(e=0)$, we fall into configuration ( $i i$ ) of Proposition 2. Consequently, the steady state is unique.

We now analyze what happens when the two conditions $(i)$ and $(i i)$ in Proposition 2 are violated. We focus our attention on the case in which $\theta^{\prime}(a)$ 
changes sign only once. In this case, $\theta(a)$ is either single-caved or singlepeaked and there are at most two steady states. Using equation (5), we have:

$$
\begin{aligned}
& \frac{d}{d a}\{\alpha(a)+\alpha(1 / a)\}= \\
& \quad \frac{1}{a}\{[1-\sigma(a)][1-\alpha(a)] \alpha(a)-[1-\sigma(1 / a)][1-\alpha(1 / a)] \alpha(1 / a)\}
\end{aligned}
$$

Using this last relation, we obtain the following results:

Proposition 3 Under the assumptions of Proposition 1, there are at most two steady states if one of the two following conditions is satisfied:

(i) $[1-\sigma(a)][1-\alpha(a)] \alpha(a)<[1-\sigma(1 / a)][1-\alpha(1 / a)] \alpha(1 / a)$, for all $a$;

(ii) $[1-\sigma(a)][1-\alpha(a)] \alpha(a)>[1-\sigma(1 / a)][1-\alpha(1 / a)] \alpha(1 / a)$, for all $a$.

Under case $(i), \theta^{\prime}(a)$ is a decreasing function. If $\theta^{\prime}(0)>0$ and $\theta^{\prime}(+\infty)<0$, then $\theta^{\prime}(a)$ changes its sign exactly once and the $\theta(a)$ function is single peaked. Under case $(i i), \theta^{\prime}(a)$ is an increasing function. Hence, if $\theta^{\prime}(0)<0$ and $\theta^{\prime}(+\infty)>0$, then $\theta^{\prime}(a)$ also changes its sign exactly once and the $\theta(a)$ function is single caved.

Therefore, if the assumptions of Proposition 1 are satisfied and $\theta^{\prime}(a)$ does not vanish at $a=1$, there are exactly two steady states whenever $(i)$ or $(i i)$ of Proposition 3 holds, provided that the appropriate boundary conditions are satisfied (namely that $\theta(a)-1$ has the same sign for $a$ close to 0 and $a$ close to $+\infty)$.

In the case where $\theta^{\prime}(a)$ vanishes for $a=1$ only one steady state exists. However, the uniqueness of the steady state does not persist and we can treat it as a non generic case. Indeed, by slightly changing $\alpha(1), \theta^{\prime}(1)$ crosses the value 0 and two steady states coexist. Later on in the paper, when local dynamics and bifurcations around the steady state are studied, it can be checked that the case just described corresponds to the emergence of a transcritical bifurcation (i.e. exchange of stability properties between two steady states). ${ }^{4}$

\footnotetext{
${ }^{4}$ For more details, see Cazzavillan, Lloyd-Braga, and Pintus (1998).
} 


\section{Local Dynamics and Bifurcation Analysis}

In this section we study the role of the marginal propensity to consume $\alpha$ and increasing returns on the emergence of deterministic and stochastic local endogenous fluctuations. In particular, we will show that:

(i) increasing returns are necessary for the occurrence of stochastic and deterministic endogenous fluctuations;

(ii) an endogenous cycle can appear if households prefer to consume the good produced in the other sector $(\alpha<1 / 2)$.

In order to do that, we assume that a steady state exists (Proposition 1) and we study its local stability and the emergence of local bifurcations using the method developed by Grandmont, Pintus, and de Vilder (1998), which applies to discrete time two dimensional dynamic systems. Therefore, we first differentiate equations (11) and (12), and we analyze local dynamics by looking at the trace $T$ and the determinant $D$ of the associated Jacobian matrix. ${ }^{5}$ In what follows, we note $\alpha=\alpha(1)$. Assuming $\alpha \neq 1 / 2$, we obtain:

$$
\begin{gathered}
D=\frac{v^{2}}{(1+e)^{2}(2 \alpha-1)} \\
T=\frac{v}{1+e} \frac{2 \alpha}{2 \alpha-1}
\end{gathered}
$$

It is possible to study the local stability of the steady state and local bifurcations by locating $(T, D)$ in the plane and studying how it varies when the value of one parameter changes continuously (see figure 1). An eigenvalue is equal to 1 when $1-T+D=0$ (line $(A C)$ ). One eigenvalue is equal to -1 when $1+T+D=0$ (line $(A B)$ ). The two eigenvalues are complex conjugate and have a modulus equal to 1 when $D=1$ and $|T|<2$ (segment $[B C]$ ). Therefore, the steady state is a sink (the two eigenvalues have modulus less than 1) if $1+T+D>0,1-T+D>0$ and $D<1$. It is a saddle (one eigenvalue has a modulus higher than one and the other has a modulus less than one) if $1-T+D>0(<0)$ and $1+T+D<0(>0)$. It is a source (the two eigenvalues have modulus higher than one) in all other cases. Suppose now that $T$ and $D$ vary when a parameter changes continuously. If the point $(T, D)$ crosses the line $(A C)$ and if one of the conditions established in Proposition 3 is satisfied, a transcritical bifurcation generically occurs. Then

\footnotetext{
${ }^{5}$ Following the Hartman-Grobman theorem, the Jacobian matrix must be inversible and must have no eigenvalue on the unit circle. See for example Grandmont (1988) and Guckenheimer and Holmes (1983).
} 
there is an exchange of stability between two steady states. When the point $(T, D)$ crosses the line $(A B)$, one gets a flip bifurcation. In this case, a cycle of period 2 appears around the steady state. Finally when the point $(T, D)$ crosses the segment $[B C]$, one gets a Hopf bifurcation, i.e. an invariant closed curve appears around the steady state. Moreover, since there is no predetermined variable in our model, the steady state is locally indeterminate when it is a sink or a saddle. Then endogenous stochastic fluctuations can occur in the neighborhood of the steady state.

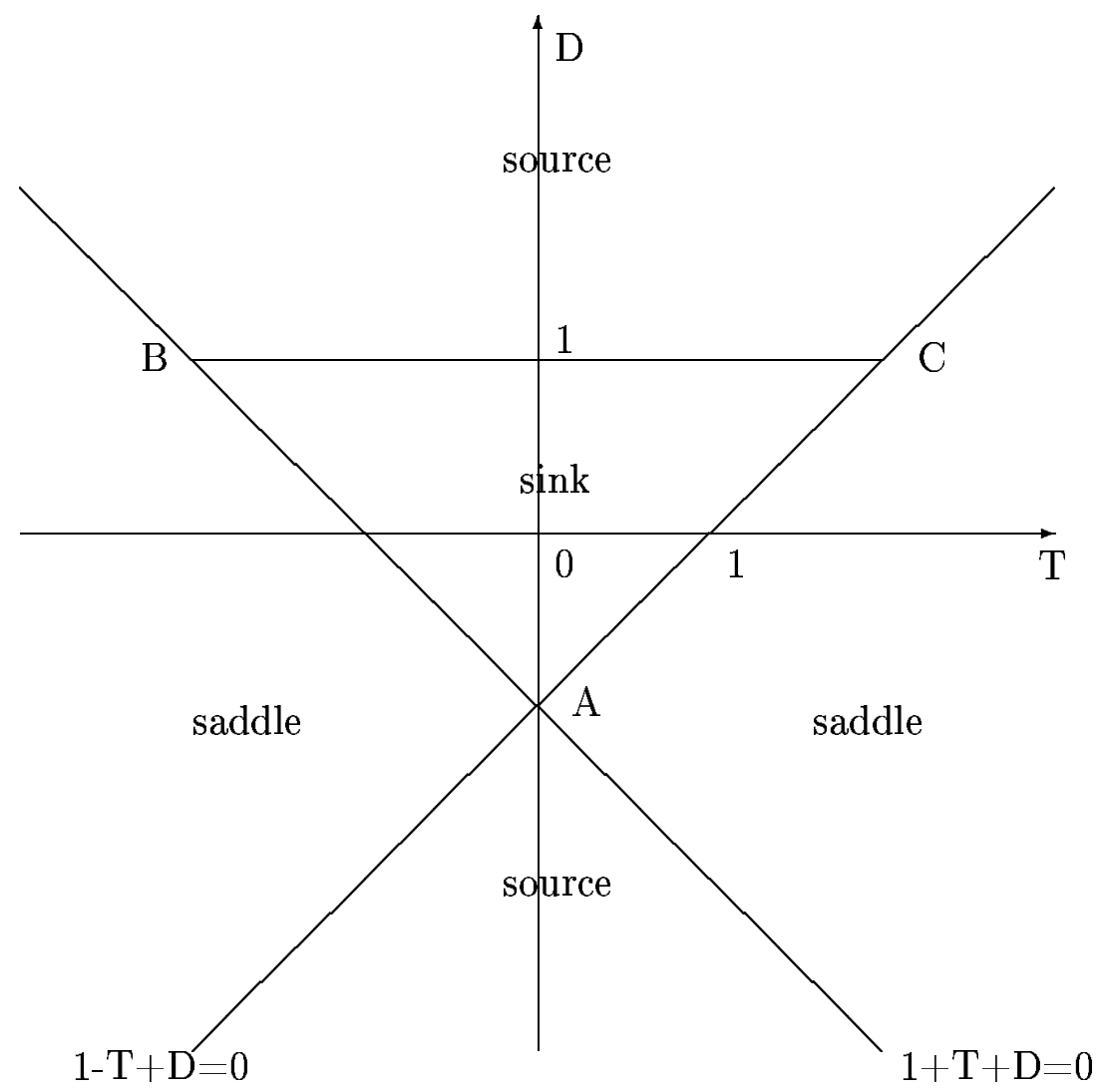

Figure 1: The Geometrical Method

We now apply this method to our economy. We study the emergence of endogenous fluctuations considering successively two cases. First, we consider that there is preference for the sector, i.e. $\alpha>1 / 2$. Secondly, we consider that there is preference for the other sector, i.e. $\alpha<1 / 2$.

\subsection{Preference for the Sector $(\alpha>1 / 2)$}

When $\alpha>1 / 2$, the determinant $D$ and the trace $T$ can be written: 


$$
\begin{gathered}
D=\frac{1}{2 \alpha-1} D_{1}, \text { with } D_{1}=\frac{v^{2}}{(1+e)^{2}} \\
T=\frac{v}{1+e}\left(\frac{1}{2 \alpha-1}-1\right)+T_{1}, \text { with } T_{1}=2 \frac{v}{1+e}
\end{gathered}
$$

The bifurcation parameter $\alpha$ can vary between $1 / 2$ and 1 which means that $1 /(2 \alpha-1) \in(1,+\infty)$. When $1 /(2 \alpha-1)$ describes $(1,+\infty)$, the point $(T, D)$ describes a half-line $\Delta_{1}$ that starts from $\left(T_{1}, D_{1}\right)$ (when $\alpha$ is close to 1 ) and whose slope $S_{1}$ is $v /(1+e)$. Moreover we can remark that $T_{1}^{2}=4 D_{1}$. Then, two cases can arise. If $v>1+e$ (i.e. the slope of the labor supply $v-1$ is greater than the slope of the labor demand $e$ ), $D_{1}$ and the slope $S_{1}$ are strictly greater than 1 . Then, the steady state is always a source. On the other hand, when $v<1+e$ (the slope of the labor supply $v-1$ is smaller than the slope of the labor demand $e$ ), $D_{1}$ and the slope $S_{1}$ are strictly smaller than 1. The half-line $\Delta_{1}$ crosses the line $(A C)$ between the point $A$ and $C$. Then, when $\alpha$ is close to 1 , the steady state is a sink. When $\alpha$ decreases $(1 /(2 \alpha-1)$ increases), a transcritical bifurcation can occur and the steady state becomes a saddle (see figure 2).

These results are summarized in the following proposition:

Proposition 4 Assuming that a steady state exists (Proposition 1), that one of the conditions established in Proposition 3 is satisfied and $\alpha>1 / 2$, then the following generically holds:

(i) if $v>1+e$, the steady state is always a source;

(ii) if $v<1+e$, the steady state is a sink when $\alpha \in\left(\alpha_{T}, 1\right)$, undergoes a transcritical bifurcation for $\alpha=\alpha_{T}$, becoming a saddle for $\alpha \in\left(1 / 2, \alpha_{T}\right)$;

where $\alpha_{T}=(1 / 2)[1+v /(1+e)]$.

This proposition establishes that when consumers prefer the good produced in their sector $(\alpha>1 / 2)$, endogenous deterministic cycle cannot emerge. However, the steady state can be locally indeterminate if increasing returns are sufficiently high, i.e. if the positive slope of labor demand $(e)$ is greater than the slope of labor supply $(v-1)$. In this case, endogenous stochastic fluctuations can appear around the steady state. Furthermore, a transcritical bifurcation can occur and there is an exchange of stability between a saddle and a sink.

We will now analyze the configuration where consumers prefer to consume the good produced in the other sector and show that an endogenous deterministic cycle can occur in this case. 


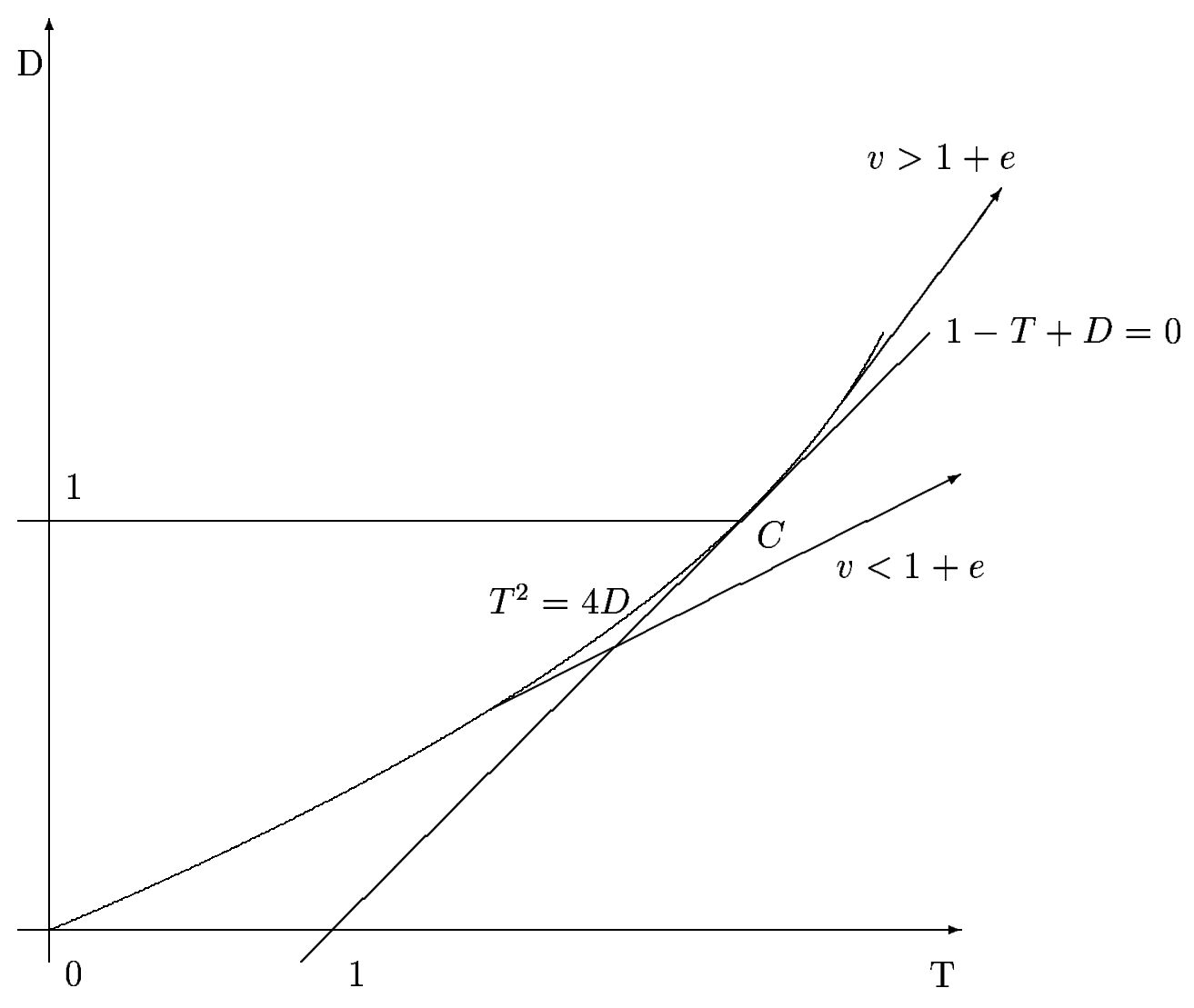

Figure 2: Preference for the Sector

\subsection{Preference for the Other Sector $(\alpha<1 / 2)$}

When $\alpha<1 / 2$, the determinant $D$ and the trace $T$ can be written:

$$
\begin{gathered}
D=\frac{1}{1-2 \alpha} D_{2}, \text { with } D_{2}=-\frac{v^{2}}{(1+e)^{2}} \\
T=-\left(\frac{1}{1-2 \alpha}-1\right) \frac{v}{1+e}
\end{gathered}
$$

First, we notice that the determinant and the trace are now both negative. Furthermore, $1 /(1-2 \alpha) \in(1,+\infty)$ because $\alpha \in(0,1 / 2)$. When $\alpha$ describes the open interval $(0,1 / 2)$, the point $(T, D)$ describes a half-line $\Delta_{2}$ that starts from $\left(0, D_{2}\right)$ (when $\alpha$ is close to 0 ), and whose slope $S_{2}$ is equal to $v /(1+e)>0$. If $v>1+e, D_{2}<-1$ and $S_{2}>1$. Then, the steady state is always a source. If $v<1+e, D_{2}>-1$ and $S_{2}<1$. Then, the steady state is a sink for values of $\alpha$ sufficiently close to 0 . When $\alpha$ increases $(1 /(1-2 \alpha)$ 
increases), a flip bifurcation can occur and the steady state becomes a saddle (see figure 3).

We can summarize these results in the following proposition:

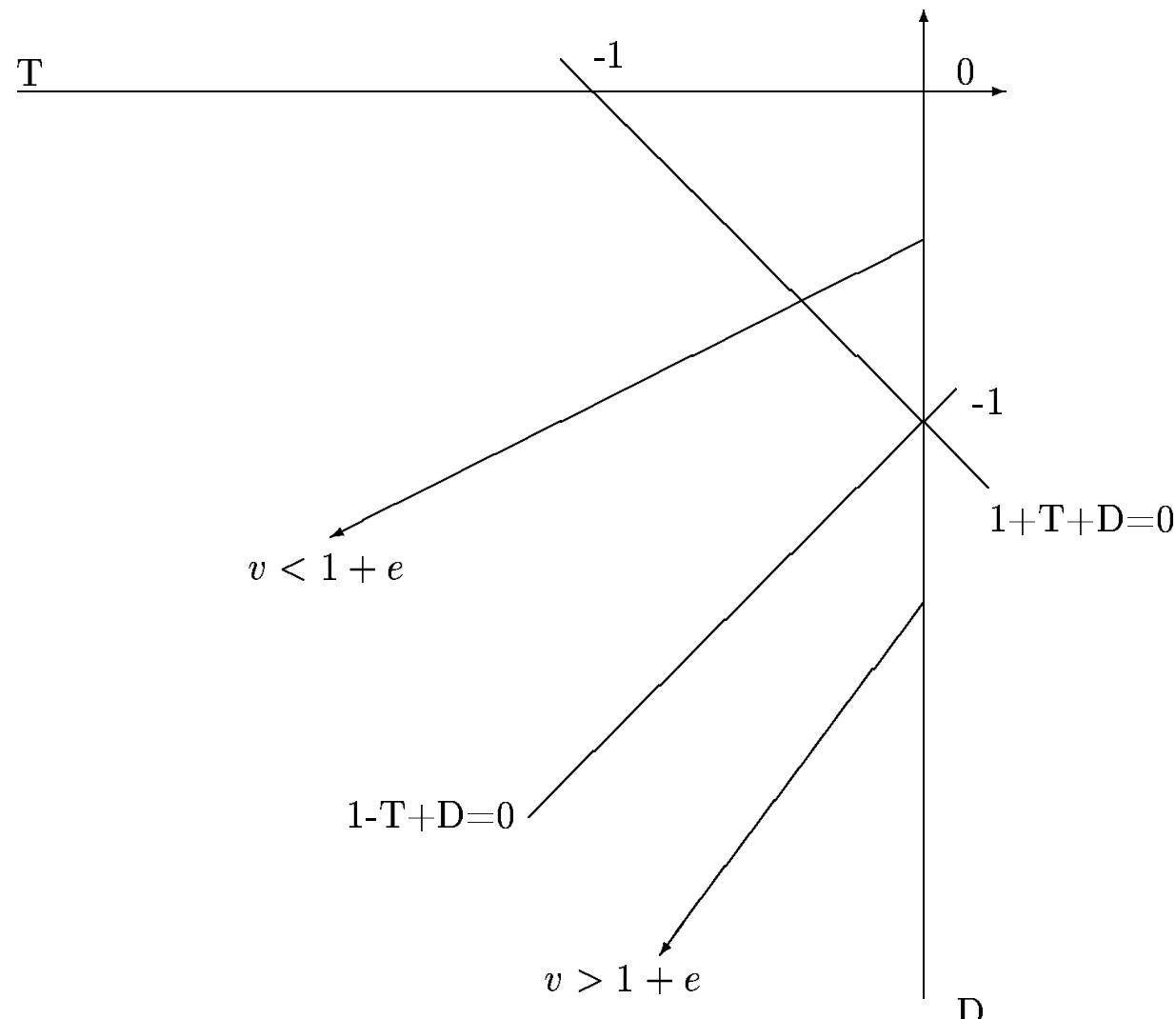

Figure 3: Preference for the Other Sector

Proposition 5 Assuming that a steady state exists (Proposition 1) and $\alpha<$ $1 / 2$, then the following generically holds:

(i) if $v>1+e$, the steady state is always a source;

(ii) if $v<1+e$, the steady state is a sink when $\alpha \in\left(0, \alpha_{F}\right)$, undergoes a fip bifurcation when $\alpha=\alpha_{F}$, becoming a saddle for $\alpha>\alpha_{F}$;

where $\alpha_{F}=(1 / 2)[1-v /(1+e)]$.

This proposition establishes that endogenous stochastic fluctuations can emerge if increasing returns are sufficiently high, i.e. if the slope of labor demand $(e)$ is greater than the slope of labor supply $(v-1)$, as in the previous 
proposition. However, in contrast to the case where $\alpha>1 / 2$, endogenous cycles can also appear through the occurrence of flip bifurcations. So, deterministic fluctuations can emerge in this economy, if households prefer to consume the good produced in the other sector. It is interesting to notice that the existence of cycles depends on the marginal propensity to consume the good produced in the sector $\alpha$, but does not depend on the elasticity of substitution between the good produced in the sector and the good produced in the other sector $\sigma$. The substitutability or complementarity between the two goods does not have any influence on local dynamics.

\subsection{Discussion}

In this section, we discuss the economic interpretations of our results. We have shown in Proposition 4 and Proposition 5 that stochastic endogenous fluctuations can emerge if increasing returns are high enough and that endogenous cycles can occur in this case only if households prefer to consume the good produced in the other sector. These results can be explained as follows.

First, consider the following simple one-sector overlapping generations model. Households supply labor at the first period, save in the form of money and consume the final good when they are old. We assume that there is intertemporal substitutability. Then, the labor supply is increasing with respect to the real wage. Firms produce the final good using only one input, labor, under a constant returns to scale technology. Assume further that the economy is at the steady state. An increase in future price pushes the labor supply to the left and employment decreases, real wages being constant under the constant returns assumption. The increase of future price also decreases future consumption and then future employment needed for the production of the final good. This excludes non monotonic orbits and endogenous fluctuations.

Consider now that there are increasing returns to scale and assume that the slope of labor demand is greater than the slope of labor supply at the steady state. A higher future price increases employment and real wages and, as before, also decreases future consumption and employment. However these non monotonic trajectories cannot be deterministic because smaller future consumption and greater employment are not compatible when the leisure and the next period consumption are gross substitutes. Hence, only local stochastic endogenous fluctuations can emerge.

Finally, consider the two-sector overlapping generations economy that we have studied in this paper. We have shown that endogenous cycles of period two can occur if households prefer to consume the good produced 
in the other sector. In order to explain the emergence of cycles, assume that the future price of the good produced in the sector increases and the future price of the good produced in the other sector decreases. If households prefer to consume the good produced in the other sector, it increases the future aggregate consumption. It also increases employment in the sector because there is intertemporal substitutability. Moreover, the increase of the future price of the good produced in the sector leads to a decrease of future employment in the sector. Then, the existence of a deterministic cycle is now compatible with the intertemporal substitutability assumption and an increasing labor supply.

\section{Conclusion}

As it is well-known, endogenous deterministic cycles cannot emerge in onesector monetary overlapping generations economy when there is intertemporal substitutability, even if returns to scale are increasing (Grandmont (1985), Lloyd-Braga (2000)). In this paper, we show that the conclusions are different when we consider a two-sector monetary overlapping generations model. In our framework, one final good is produced in each sector and households of each sector consume the two goods produced in the economy. Studying local dynamics, we obtain an usual condition for the indeterminacy of the steady state: the (positive) slope of labor demand must be greater than the slope of labor supply. But more interestingly, endogenous deterministic cycles can occur if households of each sector prefer to consume the good produced in the other sector. Then, in contrast to one-sector models, endogenous deterministic fluctuations can emerge when there is intertemporal substitutability and the labor supply is an increasing function of the real wage.

\section{References}

Aloi, M., H. D. Dixon, And T. Lloyd-Braga (2000): "Endogenous Fluctuations in an Open Economy with Increasing Returns to Scale," Journal of Economic Dynamics and Control, 24, 97-125.

BenhabiB, J., And R. E. A. FARmer (1994): "Indeterminacy and Increasing Returns," Journal of Economic Theory, 63, 19-41.

(1996): "Indeterminacy and Sector-specific Externalities," Journal of Monetary Economics, 37, 421-443. 
Benhabib, J., and K. Nishimura (1985): "Competitive Equilibrium Cycles," Journal of Economic Theory, 35, 284-306.

(1998): "Indeterminacy and Sunspots with Constant Returns," Journal of Economic Theory, 81, 58-96.

Benhabib, J., K. Nishimura, and A. Venditti (2002): "Indeterminacy and Cycles in Two-Sector Discret-Time Models," Economic Theory, 20, $217-235$.

Cazzavillan, G., T. Lloyd-Braga, and P. Pintus (1998): "Multiple Steady States and Endogenous Fluctuations with Increasing Returns to Scale in Production," Journal of Economic Theory, 80, 60-107.

Chatterjee, S., R. Cooper, and B. Ravikumar (1993): "Strategic Complementarity in Business Formation: Aggregate Fluctuations and Sunspot Equilibria," Review of Economic Studies, 60, 795-811.

Galor, O. (1992): "A Two-Sector Overlapping Generations Model: a Global Characterization of the Dynamical System," Econometrica, 60, 1351-1386.

Grandmont, J.-M. (1985): "On Endogenous Competitive Business Cycles," Econometrica, 53, 995-1045.

(1988): "Nonlinear Difference Equations, Bifurcation and Chaos: an Introduction," Working Paper 8811, CEPREMAP.

Grandmont, J.-M., P. Pintus, And R. DE Vilder (1998): "Capitallabour Substitution and Competitive Nonlinear Endogenous Business Cycles," Journal of Economic Theory, 80, 14-59.

GuCKenheimer, J., And P. Holmes (1983): Nonlinear Oscillations, Dynamical Systems, and Bifurcations of Vector Fields. Springer-Verlag, NewYork.

Harrison, S. G., AND M. Weder (2002): "Tracing Externalities as Sources of Indeterminacy," Journal of Economic Dynamics and Control, 26, 851867.

JaCoBsen, H. J. (2000): "Endogenous, Imperfectly Competitive Business Cycles," European Economic Review, 44, 305-336.

Lloyd-Braga, T. (2000): "Increasing Returns to Scale and Nonlinear Endogenous Fluctuations in a Simple Overlapping Generations Model: a Pedagogical Note," Annales d'Economie et de Statistique, 59, 89-106. 
Reichlin, P. (1986): "Equilibrium Cycles in an Overlapping Generations Economy with Production," Journal of Economic Theory, 40, 89-103. 